\title{
Application of Data Mining in Effect Evaluation of Lean Management
}

\author{
Song Ding, ${ }^{1}$ Jun $\mathrm{Li}^{2}$ and Jiye $\mathrm{Li} \mathbb{i D}^{3}$ \\ ${ }^{1}$ School of Economics and Management, Chengdu Technology University, Chengdu, Sichuan 611730, China \\ ${ }^{2}$ Office of Teaching Construction and Quality Control in Chengdu Technological University, Chengdu, Sichuan 611730, China \\ ${ }^{3}$ School of Computer Engineering in Chengdu Technology University, Chengdu, Sichuan 611730, China
}

Correspondence should be addressed to Jiye Li; ljyybf123@cdtu.edu.cn

Received 9 November 2021; Revised 22 November 2021; Accepted 21 December 2021; Published 10 January 2022

Academic Editor: Baiyuan Ding

Copyright (C) 2022 Song Ding et al. This is an open access article distributed under the Creative Commons Attribution License, which permits unrestricted use, distribution, and reproduction in any medium, provided the original work is properly cited.

\begin{abstract}
Quantitative evaluation is an important part of enterprise diagnosis, which promotes the scientific and modern management of enterprises. At present, the existing enterprise management evaluation methods cannot complete the mining of enterprise index data, which leads to large error and low significance coefficient in enterprise management evaluation. Therefore, the application of data mining in enterprise lean management effect evaluation is put forward. The process and main functions of data mining are analyzed; data mining algorithm is used to establish the evaluation index system of lean management effect and calculate the index weight. Using the association rules method in data mining, according to the parameters of enterprise lean management level evaluation index and weight value, through the fuzzy set transformation idea, the fuzzy boundary of each index and factor is described by the membership degree, the fuzzy judgment matrix is constructed, and the final evaluation result is obtained by multilayer compound calculation. Experimental results show that this study has a high significance coefficient, and the proposed evaluation method of enterprise lean management effect has ideal accuracy and short time consumption. In practical application, the cumulative contribution rate is higher and has higher stability.
\end{abstract}

\section{Introduction}

With the continuous improvement of the national economy, a large number of new types of enterprises have emerged. There are still some problems in the management of enterprises, such as improper management mode and imperfect related systems. Therefore, it is necessary to adopt lean management mode, innovate enterprise management mode and technology continuously to ensure the increasing economic benefits of enterprises, and highlight the pursuit of high quality and high efficiency. Lean management requires lean thinking in all aspects of business. The core is to create a large amount of value with the minimum investment of resources and to provide users with new products and timely services [1]. Lean management not only strengthens the informationization control to the manufacture and the production link of the company's products, but also pays more attention to the overall operation and the optimization of the operation link, involving all the management details of the company and the production details of the products, and all the project flows of these enterprises are related to the cost. The focus of lean management is to optimize the product processing and manufacturing, daily operation and management, material management and storage, technological innovation and development, and other aspects during the stable operation stage of the company [2].

Lean management is a new type of company management and operation, concepts and methods, and scientific and technological tools, such as a unified scientific system. In this way, value stream is the focus of management, and striving for perfection is an important content of management pursuit. We shall build up a "people-oriented" corporate culture, adopt the purpose of systematic thinking, and fully absorb and adopt a variety of advanced methods and scientific and technological methods under the guidance of the broad sense of lean philosophy in the strategic technical 
level and each subsystem of the company. Through business process reengineering, innovate the value stream, fully adapt to users and meet user requirements, maximize the company's value, and achieve win-win with relevant partners. Create a learning organization, implement lean strategy, establish lean operation system, develop economic and financial software, understand lean technology, strengthen lean cost control, create a kind of lean management style and harmonious company environment, and continuously optimize.

Reference [3] explores the choice of cooperation strategies among participants in new R\&D institutions by using evolutionary game model under the premise of bounded rationality hypothesis. By analyzing the multiagent income payment matrix and solving the replication dynamic equation and Jacobian matrix, the local equilibrium point of the model is obtained so as to obtain the final strategy choice of all participants over time, verify the strategy evolution trend of the game system through numerical simulation, and sort out the influencing factors of the strategy choice of new R\&D institutions under cooperative innovation. On this basis, this paper puts forward strategic suggestions to realize the sustainable development of new $R \& D$ institutions from the perspectives of cooperation mode, enterprise demand, and policy environment. This method completes the selection of cooperation strategy among participants, but it is unable to complete the index data mining of R\&D institutions. In [4], the credit risk evaluation model of small enterprises based on ELECTRE III is studied. Firstly, based on the evaluation principle of ELECTRE III, the credit risk evaluation score of new loan customers is calculated according to the net credibility of new loan customers better than all historical loan customers. It not only solves the problem of credit risk evaluation of new loan customers, but also ensures that the evaluation model has the ability to learn from historical data. Secondly, referring to the characteristics that Theil's index can not only reflect the overall income difference, but also decompose the overall difference into intragroup difference and intergroup difference; the evaluation indexes of small enterprise credit risk are weighted. It embodies the weighting idea of "the more you can distinguish the default status of customers, the greater the weight of indicators." Finally, based on the weighted intragroup difference between default and nondefault samples, the preference threshold of ELECTRE III is determined. Determine the indifference threshold of ELECTRE III based on the degree of difference within the nondefault group. Based on the difference degree within the default sample group, the rejection threshold of ELECTRE III is determined. This method not only reflects the influence of the data difference of different evaluation indexes on the evaluation results, but also avoids the deficiency of artificial and subjective determination of the existing threshold. However, it is easy to lead to large error in the evaluation of enterprise management effect. A nonrelational distributed big data mining algorithm is proposed in [5]. Firstly, the distributed maximum frequent item algorithm model is introduced. Under the physical decentralized logic, the distributed method is applied to the nonrelational data for data analysis, the search conditions of candidate frequent items are established to reduce the number of data detected, and the partition projection method is adopted to calculate the partition number corresponding to each frequent item and plan it into different partitions so as to optimize the redundant frequent items. Then, according to the data characteristics of big data in the database, the correlation degree of each attribute is established. According to the boosting clustering method, the local model obtained by weak clustering is upgraded to the global model in each iteration, and then it is divided into blocks. Using the partition quality to readjust the iterative sampling rate, the final clustering results are obtained and the data mining is completed. It has a good effect, but the significance coefficient of this method is low.

However, the above reference methods cannot complete the mining of enterprise index data, resulting in large error and low significance coefficient in the evaluation of enterprise management effect. Therefore, this paper puts forward the application research of data mining in enterprise lean management effect evaluation.

\section{Enterprise Lean Management Effect Evaluation Based on Data Mining}

2.1. Data Mining Process and Main Functions. Data mining is a kind of technology that is mainly used by different subjects, and it is of great importance in every field. Data mining refers to the process of extracting useful knowledge from large, incomplete, noisy, and vague data $[6,7]$. It comes from knowledge extraction in database, namely, KDD. People use $\mathrm{KDD}$ to depict the whole process of data mining and use data mining to describe the basic process of mining algorithm to achieve data mining [8]. The process of discovering valuable knowledge in the database, known as the KDD process, is shown in Figure 1.

According to Figure 1, KDD is composed of data collection and processing, data information mining and result analysis, etc. Data mining is mainly based on association analysis, cluster analysis, and prediction to find useful knowledge in large-scale data. At the same time, through model evaluation, valuable models are used as knowledge to assist related personnel to make scientific and rational decisions.

The main function of data mining is to make decisions based on valuable knowledge by predicting the future development trend. The main function of data mining technology is not realized by a single way, but by a group of methods. The main task of data mining is to find valuable knowledge or information from relevant databases. The main functions of data mining are as follows $[9,10]$ :

\section{(1) Correlation Analysis of Data}

In a database, the analysis of the correlation between data is the key link to discovering important knowledge. If there is some special law between two or more variable values, it can be called an association. 


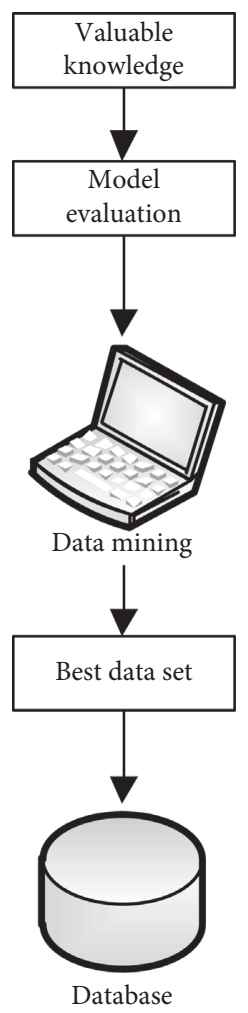

Figure 1: Overall flow of KDD.

\section{(2) Cluster Analysis between Data}

In a database, the data information records can be divided into different meaningful data subsets; the process is data clustering. Among them, the smaller the distance between the data in the same data class, the more similar they are, and dissimilar they are. Data clustering can enhance people's cognition of objective facts, and it is the precondition of concept representation and deviation analysis. At present, there are several data clustering algorithms in common use: mean clustering, density clustering, fuzzy clustering, and so on [11].

\section{(3) Forecast Analysis}

In some instances, the public may have to predict some vacant values. If the data for the vacant value is a numeric type, it is generally called a forecast. The process of forecasting is as follows: searching for the laws between the data and information according to the historical data, constructing a corresponding model, and forecasting the following data based on the model [12].

\section{(4) Data Evolution Analysis}

In a database, the evolution analysis of data information indicates that there are laws and trends in the target of a certain behavior changing with time, and at the same time, the trend is modeled.

\subsection{Evaluation Index System of Enterprise Lean Management} Effect. The enterprise management effect evaluation index system can measure the intensity of the impact of scientific and technological production factors on industrial transformation and development. According to the characteristics of industrial upgrading and scientific and technological production, and on the basis of the basic principles of index system construction, the enterprise management effect evaluation index is selected from factor flow and factor composition [13]. The content of Constructing Indicators mainly includes input dimension, status dimension, and evaluation dimension. Among them, human input, financial input, and material input constitute the input dimension. Personnel activities, fund use, implementation form, R\&D output, and achievement transformation constitute the state dimension. The upgrading of industrial structure, the rationalization of industrial structure, the dual orientation of industrial development, and the transformation of industrial development constitute the evaluation dimensions.

The basis for establishing the enterprise operation effect evaluation index system shall follow the following basic principles:

(1) Scientific principle: this is the basic principle that should be followed in the setting of enterprise operation effect evaluation index system. According to this principle, the setting of indicators and indicator system should be consistent with the idea of circular economy and the concept of enterprise operation effect evaluation. Therefore, the concept of indicators should be accurate, the connotation and extension should be clear, and the calculation method should be scientific and feasible.

(2) The principle of combining qualitative measurement with quantitative measurement: this principle is a higher-level requirement for the setting of index system. Because only quantitative indicators can be used to evaluate the enterprise's operation effect from one level, the evaluation results are not comprehensive and one-sided, and the enterprise's operation effect cannot be truly evaluated. If qualitative indicators are set on the basis of quantitative indicators, from a higher level, by investigating various measurement factors that have a direct impact on the operation effect of enterprises but are difficult to be uniformly quantified, the combination of quantitative analysis and qualitative analysis can avoid the defects caused by relying solely on quantitative methods.

(3) Operability principle: there must be a clear calculation method and expression method when setting indicators so that all indicators can be easily calculated for easy operation.

(4) Comparability principle: when setting indicators, they should maintain relative stability in meaning, scope, and methods within a certain period of time, so as to facilitate the comparability of evaluation results, so as to determine the level and position of enterprises in the same industry, the same scale and in the national economy, so as to find out the gap and tap the potential. 
The constructed industrial effect evaluation index system is shown in Figure 2.

It can be seen from Figure 2 that the enterprise operation effect evaluation itself is a complex system engineering, which cannot be simply determined by a certain index. After introducing the strategic idea of lean management into the process of enterprise management, the goal of enterprise business activities has shifted from simply pursuing economic benefits to enterprises pursuing both their own economic benefits and environmental benefits. Therefore, the external performance of enterprise management effect evaluation oriented to data mining should be multidimensional, and its goal should be diversified. Therefore, the industrial effect oriented evaluation index system is a multilevel, multifactor, and multiobjective comprehensive evaluation.

Suppose $X=[x(1), x(2) \ldots x(n)]$ describes the vector of national or regional industrial structure, and $X_{0}=\left[x_{0}(1), x_{0}(2) \ldots x_{0}(n)\right]$ describes the vector of optimized objective structure of enterprise management at a certain level of economic development by means of the following primitive point zeroing:

$$
\begin{aligned}
& x^{0}(k)=x(k)-x(1), \\
& x_{0}^{0}(k)=x_{0}^{0}(k)-x_{0}^{0}(1) .
\end{aligned}
$$

The following can be obtained through formula (1):

$$
\begin{aligned}
& X^{0}=\left[x^{0}(1), x^{0}(2), \ldots, x^{0}(n)\right], \\
& X_{0}^{0}=\left[x_{0}^{0}(1), x_{0}^{0}(2), \ldots, x_{0}^{0}(n)\right] .
\end{aligned}
$$

Let $\varsigma$ represent the degree of industrial order, which can be calculated by the following formula:

$$
\varsigma=\frac{1+\left|s_{0}\right|+\left|s_{1}\right|}{1+\left|s_{0}\right|+\left|s_{1}\right|+\left|s_{0}-s_{1}\right|} .
$$

Here, $\varsigma$ describes the proximity between the proportion of the target industry structure and the current proportion of the industrial structure. The closer the two proportions are, the smaller the value of $\left|s_{0}-s_{1}\right|$ is, and the closer the degree of industrial order $\varsigma$ is to $1 ; s_{0}$ represents the level of nullification of the target industry:

$$
\left|s_{0}\right|=\left|x_{0}^{0}(2)\right|+\frac{1}{2}\left|x_{0}^{0}(3)\right| \text {. }
$$

$s_{1}$ represents the level of nullification corresponding to the actual industrial structure of the region, with the following expression:

$$
\left|s_{1}\right|=\left|x^{0}(2)\right|+\frac{1}{2}\left|x^{0}(3)\right| \text {. }
$$

The relationship between $s_{0}$ and $s_{1}$ can be described by the following formula:

$$
\left|s_{0}-s_{1}\right|=\left|x^{0}(2)-x_{0}^{0}(2)\right|+\frac{1}{2}\left|x^{0}(3)-x_{0}^{0}(3)\right| \text {. }
$$
follows:

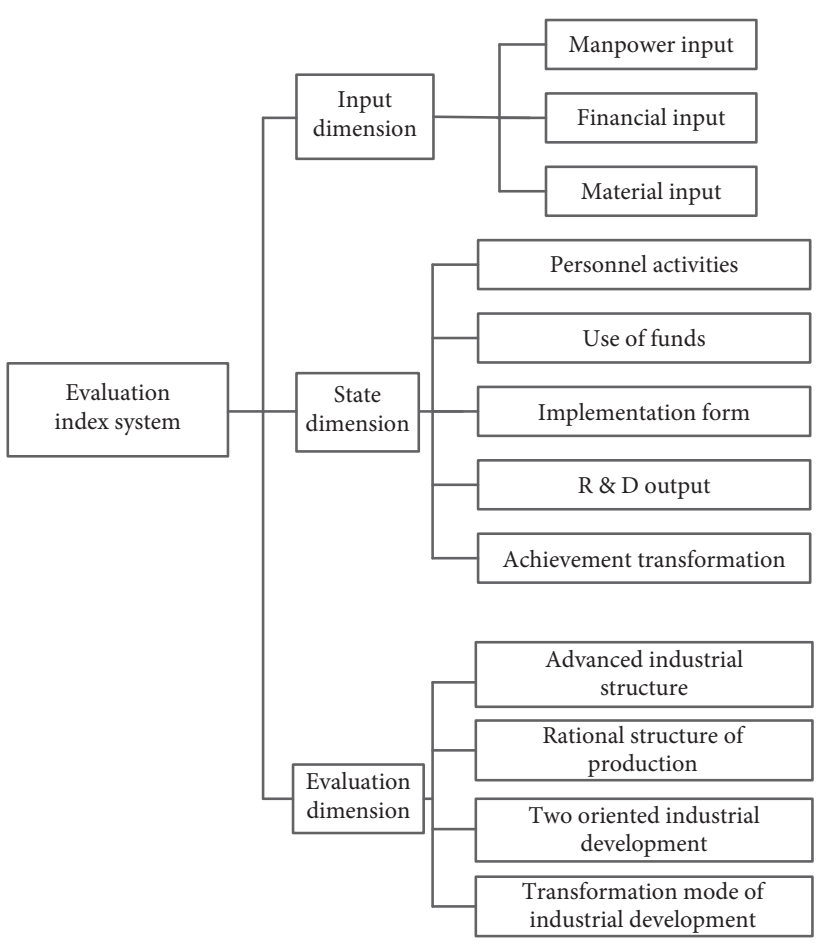

FIgURE 2: Industrial effect evaluation index system.

Step 1. Set the initial weight vector as random acquisition.

Step 2. Update the weight vector through formula (6).

Step 3. Normalization.

Step 4. If the target industrial structure proportion is close to the current industrial structure proportion, the data mining stops convergence. If it is not achieved, jump back to Step 2 and continue to execute until an independent component is estimated.

If you want to realize multicomponent extraction, you can repeatedly execute the data mining algorithm for separation. At the same time, if you need to judge that the components extracted each time are not similar components, you need to complete one component extraction at a time, remove the component from the observation signal, and repeat the elimination operation; that is, you can extract all the required independent components. After execution, it can realize the denoising of the original spatial attribute data.

2.2.1. Single Indicator Evaluation. There are different positive and negative trends and different units of measurement between different index values. The index value of enterprise management effect evaluation is nondimensionalized and trended by single index evaluation $[14,15]$.

The following formula shall be used to make the evaluation indicators of negative enterprise management effect co-trend: 


$$
y_{i j}=\max _{1 \leq i \leq m}\left\{x_{i j}\right\}-x_{i j} .
$$

In the formula, $i=1,2, \ldots, m, j=1,2, \ldots, n ; y_{i j}$ is the value after the $j$ industrial effect evaluation index of the $i$ evaluated object in the same trend processing; $x_{i j}$ describes the statistical value corresponding to the $j$ industrial effect evaluation index of the $i$ evaluated object.

Dimensionless average treatment shall be carried out on the evaluation indexes of management effect of a single enterprise through the following formula [16]:

$$
Y_{i j}=\frac{y_{i j}}{\bar{y}_{j}} .
$$

Here, $Y_{i j}$ describes the value obtained without quantization processing and $\bar{y}_{j}$ describes the average value of the $j$ industrial effect evaluation index.

2.2.2. Index Weight. The research method of enterprise management effect evaluation calculates the weight of the enterprise management effect evaluation index through coefficient of variation method [17].

The coefficient of variation method assigns the value of each industrial effect evaluation index through the variation degree of the observed value of each industrial effect evaluation index on the evaluated object [18]. Therefore, the difference of each evaluation object can be reflected by the index of large variation degree of observation value.

Set $x_{i j}$ to represent the evaluation value of item $j$ industrial effect evaluation index of item $i ; V_{j}$ to represent the coefficient of variation corresponding to the industrial effect evaluation index of Item $j$, and the calculation formula is as follows:

$$
V_{j}=\frac{S_{j}}{M_{j}} \times 100 \% .
$$

Here, $M_{j}$ represents the average value of the indices for evaluating the industrial effect of item $j$ of the evaluated object $i ; S_{j}$ represents the standard deviation, which is calculated by the following formulas:

$$
\begin{aligned}
M_{j} & =\frac{1}{m} \times \sum_{i=1}^{m} x_{i j}, \\
S_{j} & =\sqrt{\sum_{i=1}^{m}\left(x_{i j}-M_{j}\right) \times \frac{1}{m-1}} .
\end{aligned}
$$

The coefficient of variation $V_{j}$ of the industrial effect evaluation index of normalized treatment shall be obtained, and the weight $w_{j}$ of the industrial effect evaluation index shall be obtained:

$$
w_{j}=\frac{V_{j}}{\sum_{i=1}^{n} V_{j}} .
$$

Only long-term implementation and continuous improvement of enterprise lean management can achieve the ideal final result. Therefore, the implementation of lean management is a long-term process, which needs to go through different implementation extremes. It is also a systematic project, which needs to take into account different aspects such as personnel, technology, environment, and culture. It has established a lean management evaluation index system that takes into account results and processes.

2.3. Quality Evaluation of Enterprise Lean Management Based on Data Mining. From the above analysis, we can see that association rules are one of the most significant methods in data mining. Association rules are widely used in enterprise lean management quality management. There are a lot of matters involved in enterprise lean management quality management, such as courses and evaluation index, etc. Association rules can extract valuable knowledge hidden in data, assist educational administrators to make effective decisions, and improve the management level [19-21].

According to the determination of such parameters as the evaluation index and weight of lean management level of enterprises, the fuzzy boundary of each index and factor is described by the membership degree through the idea of fuzzy set transformation, and the fuzzy judgment matrix is constructed, and the final evaluation result is obtained by multilayer compound calculation [22].

There are $n$ evaluation grades and $m$ Grade I evaluation indexes. Each Grade I index contains several Grade II indexes, which are represented by Grade $U$, Grade I index scope $V$, and Grade II index scope $V_{i}$, and are as follows:

$$
\begin{aligned}
U & =\left\{u_{1}, \ldots, u_{n}\right\}, \\
V & =\left\{v_{1}, \ldots, v_{n}\right\}, \\
V_{i} & =\left\{v_{1}, \ldots, v_{k}\right\} .
\end{aligned}
$$

The fuzzy matrix can be expressed as follows [23]:

$$
U=\left[\begin{array}{c}
V_{1} \\
V_{2} \\
\vdots \\
V_{m}
\end{array}\right]\left[\begin{array}{cccc}
U_{11} & u_{12} & \cdots & u_{1 n} \\
U_{21} & u_{22} & \cdots & u_{2 n} \\
\vdots & \vdots & \cdots & \vdots \\
U_{m 1} & u_{m 2} & \cdots & u_{m n}
\end{array}\right]=\left[u_{i j}\right]_{m n}
$$

Here, $u_{i j}$ represents the degree of membership of the evaluation index $i$ to Grade $j$ [24-26].

Based on the above calculation and analysis, the fuzzy relation matrix is obtained, and the weight value of the firstgrade evaluation index can be defined as follows:

$$
\mathfrak{R}=\left(\mathfrak{R}_{1}, \mathfrak{R}_{2}, \ldots, \mathfrak{R}_{m}\right) \text {. }
$$

The Grade I evaluation index is divided into very good $(A)$, good $(B)$, better $(C)$, poor $(d)$, and very poor $(E)$. The evaluation index grade standard is shown in Table 1 .

Combined with the above calculation and Table 1, the enterprise lean management quality evaluation model can be expressed as follows [27, 28]:

$$
W=\mathfrak{R} \times C \times U .
$$


TABle 1: Evaluation index grade standard.

\begin{tabular}{lcc}
\hline Evaluation grade & Critical value (\%) & Weight (\%) \\
\hline A & 100 & 31.7 \\
B & 80 & 29.2 \\
C & 60 & 26.2 \\
D & 40 & 18.5 \\
E & 20 & 14.3 \\
\hline
\end{tabular}

The fuzzy comprehensive evaluation and data mining methods are used to construct the enterprise lean management quality evaluation model, which fully considers the fault-tolerance of the evaluation process and other aspects, and can effectively improve the modeling freedom and reduce the modeling complexity [29-31]. From the above evaluation results of the lean management effect of the enterprise, it can be seen that the implementation of data mining technology in the enterprise has improved the overall quality of the enterprise, improved the enterprise management system, and achieved obvious economic and environmental benefits. Lean management is the mainstream economic model for the development of the new era. If enterprises want to survive, develop, and make profits in the new century, they must infiltrate the idea of lean management into every corner of the enterprise. In order to evaluate the effect of lean management oriented to data mining, it is necessary to establish an enterprise operation evaluation index system oriented to lean management. In practical application, enterprises can increase or decrease the evaluation indicators according to the specific situation so as to better evaluate the effect of lean management.

\section{Experimental Results and Analysis}

In order to further study the impact of internal control, customer relationship maintenance, and financial management on the effect of lean management innovation, this paper constructs a method of lean management effect evaluation.

3.1. Selection of Variables and Establishment of the Model. The explanatory variable in the regression model [32] is enterprise lean management effect MAP. In order to simplify the calculation of the model, this paper substitutes variable EPS per share for enterprise lean management effect [33]. The explanatory variables are internal control effect ICE34, customer relationship maintenance effect CRM [35], and financial management level FML [36], and the relevant control variables are selected and designed as shown in Table 2.

After the control variables of the regression model are determined, the unknown parameters of the model are estimated by using the sample data, and the multiple regression linear regression model is designed as follows:

$$
\begin{aligned}
\mathrm{EPS}= & e+\gamma_{0}+\gamma_{1} \mathrm{ICE}+\gamma_{2} \mathrm{CRM}+\gamma_{3} \mathrm{FML}+\gamma_{4} \mathrm{ESIZE} \\
& +\gamma_{5} \mathrm{BSIZE}+\gamma_{6} \mathrm{DR}+\gamma_{7} \mathrm{EC} .
\end{aligned}
$$

Here, $\gamma_{0}$ is the model constant, $\gamma_{1}-\gamma_{3}$ are the explanatory variable coefficient, $\gamma_{4}-\gamma_{7}$ are the control variable coefficient, and $e$ is the residual term of the model. Whether the model really reveals the relationship between the explained variables and the explanatory variables requires the establishment of multiple linear regression equations based on the actual observation data of dependent variables and multiple independent variables, and the linear relationship between the dependent variable and multiple independent variables is only a hypothesis. Although this hypothesis is often not groundless, after establishing the multiple regression linear regression model, it is also necessary to test the significance of the hypothesis of the linear relationship between dependent variables and multiple independent variables, that is, to test the significance of multiple linear regression relationship or to test the significance of multiple linear regression model.

\subsection{Selection of Sample Data and Descriptive Statistical} Analysis of Variables. From the sample data of lean management behaviors of enterprises in a city from 2017 to 2020, 75 enterprises and 86 enterprises are selected, respectively, and the time node for the selected enterprises to conduct lean management behaviors shall be June 2018. ST enterprises with abnormal operating performance shall be excluded, samples of abnormal financial data or financial reports shall be excluded, enterprises of less than three years of listed companies shall be excluded, financial and insurance listed enterprises with obvious industry specificity shall be excluded, and the last 123 research samples shall be excluded. The selected sample enterprises have assets of more than 2 billion people, among which there are 36 enterprises with assets of 2-5 billion and 87 enterprises with assets of more than 5 billion. From the scale of the sample, we can see that the asset strength of the enterprise is strong, and it has the precondition of lean management, and it is helpful to control the financial risk.

Based on the SPSS 24.1 statistical analysis software, the descriptive statistical analysis of each variable is performed as shown in Table 3.

From 2017 to 2020, the change trend of the EPS-means of the variables can be seen, from -0.0357 to 0.5499 , which shows that the EPS index after M\&A shows an increasing trend, and the level of business risks and financial risks of enterprises is also decreasing. Then, analyze the correlations among the explanatory variables, control variables, and explained variables $B$ of the enterprise before and after the merger, and the statistical analysis results are as shown in Tables 3-6. The symbols *, ${ }^{* *}$, and ${ }^{* * *}$ in Tables $4-7$ indicate statistical significance in the range of $10 \%, 5 \%$, and $1 \%$.

From the correlation data of each explanatory variable and EPS of the explanatory variable, it can be seen that there is a negative correlation between ICE, CRM, and FML before M\&A in 2014 and 2015 and the proportion of the explanatory variable, while in 2016 and 2017 after the enterprise implements lean management, the correlation coefficient between the explanatory variables and the coefficient of the explanatory variable is high, which 
TABLE 2: Selection of control variables of the regression model.

\begin{tabular}{lcc}
\hline Control variable & Code & Relevant description \\
\hline Enterprise scale & ESIZE & Natural logarithm of asset scale in the year before lean management \\
Lean management scale & BSIZE & Lean management transaction volume/total assets at the end of the year \\
Debt ratio & DC & Total liabilities/total assets of the enterprise \\
Equity concentration & Shareholding ratio of the top 5 shareholders of the enterprise \\
\hline
\end{tabular}

TABLE 3: Descriptive statistical analysis results of variables.

\begin{tabular}{|c|c|c|c|c|c|c|}
\hline Variable & & Number of samples & $\min$ & $\max$ & $\bar{\mu}$ & $\sigma$ \\
\hline \multirow{4}{*}{ EPS } & 2017 & 200 & -0.2534 & 0.4552 & -0.0357 & 0.0035 \\
\hline & 2018 & 200 & -0.5524 & 0.5254 & 0.0450 & 0.0240 \\
\hline & 2019 & 200 & 0.5324 & 0.3524 & 0.5979 & 0.2558 \\
\hline & 2020 & 200 & 0.2357 & 5.4255 & 0.5499 & 0.5329 \\
\hline$I C E$ & & 200 & 500 & 3.3037 & 2.2548 & 0.3358 \\
\hline CRM & & 200 & 500 & 0.3425 & 0.5254 & 0.0005 \\
\hline$F M L$ & & 200 & 500 & 0.3984 & 0.5949 & 0.5205 \\
\hline ESIZE & & 200 & 500 & 0.8524 & 0.3255 & 0.0047 \\
\hline$B S I Z E$ & & 200 & 500 & 5.2545 & 0.8748 & 0.5534 \\
\hline$D R$ & & 200 & 500 & 52.2545 & 4.8455 & 5.3325 \\
\hline$E C$ & & 200 & 500 & 3.3254 & 4.2544 & 0.0354 \\
\hline
\end{tabular}

TABLE 4: Correlation statistics between model variables in 2017.

\begin{tabular}{|c|c|c|c|c|c|c|c|c|}
\hline Variable & $E P S$ & ICE & CRM & $F M L$ & $E S I Z E$ & $B S I Z E$ & $D R$ & $E C$ \\
\hline$E P S$ & 1 & - & - & - & - & - & - & - \\
\hline$I C E$ & $-0.231^{*}$ & 1 & - & - & - & - & - & - \\
\hline$C R M$ & $-0.235^{* *}$ & 0.025 & 1 & - & - & - & - & - \\
\hline$F M L$ & 0.057 & -0.359 & -0.811 & 1 & - & - & - & - \\
\hline ESIZE & $0.015^{* *}$ & $0.256^{*}$ & 0.369 & $0.125^{* *}$ & 1 & - & - & - \\
\hline$B S I Z E$ & -0.0415 & $0.287^{* *}$ & $0.448^{* * *}$ & $0.484^{*}$ & $0.015^{*}$ & 1 & - & - \\
\hline$D R$ & 0.027 & $0.590^{* * *}$ & $0.458^{*}$ & 0.744 & -0.999 & 0.362 & 1 & - \\
\hline$E C$ & -0.371 & $0.581^{*}$ & $0.012^{*}$ & $0.559^{* * *}$ & 0.072 & 0.005 & 0.168 & 1 \\
\hline
\end{tabular}

TABLE 5: Correlation statistics between model variables.

\begin{tabular}{|c|c|c|c|c|c|c|c|c|}
\hline Variable & EPS & $I C E$ & $C R M$ & $F M L$ & $E S I Z E$ & $B S I Z E$ & $D R$ & $E C$ \\
\hline EPS & 1 & - & - & - & - & - & - & - \\
\hline$I C E$ & $-0.066^{*}$ & 1 & - & - & - & - & - & - \\
\hline CRM & $-0.128^{* *}$ & $0.036^{*}$ & 1 & - & - & - & - & - \\
\hline$F M L$ & $-0.005^{* * *}$ & $-0.093^{*}$ & 0.285 & 1 & - & - & - & - \\
\hline$E S I Z E$ & $0.149^{*}$ & $0.245^{*}$ & $-0.283^{* *}$ & $0.356^{* *}$ & 1 & - & - & - \\
\hline$B S I Z E$ & $0.018^{*}$ & $0.858^{* *}$ & $0.448^{* * *}$ & $0.484^{*}$ & $0.015^{*}$ & 1 & - & - \\
\hline$D R$ & $0.158^{*}$ & $0.699^{* *}$ & $0.414^{*}$ & $0.778^{* *}$ & $-0.115^{* *}$ & $0.758^{* *}$ & 1 & - \\
\hline$E C$ & -0.121 & $0.238^{*}$ & $0.021^{* *}$ & $0.550^{* *}$ & $0.654^{*}$ & $0.152^{* *}$ & $0.256^{*}$ & 1 \\
\hline
\end{tabular}

TABLE 6: Correlation statistics between model variables in 2019.

\begin{tabular}{|c|c|c|c|c|c|c|c|c|}
\hline Variable & EPS & $I C E$ & CRM & $F M L$ & ESIZE & $B S I Z E$ & $D R$ & $E C$ \\
\hline$E P S$ & 1 & - & - & - & - & - & - & - \\
\hline$I C E$ & $0.282^{* *}$ & 1 & - & - & - & - & - & - \\
\hline CRM & $0.369^{* *}$ & $0.079^{*}$ & 1 & - & - & - & - & - \\
\hline$F M L$ & $0.269^{*}$ & $0.331^{*}$ & $0.689^{* * *}$ & 1 & - & - & - & - \\
\hline$E S I Z E$ & $0.545^{* *}$ & $0.667^{*}$ & $0.969^{* * *}$ & $1.365^{* *}$ & 1 & - & - & - \\
\hline$B S I Z E$ & $0.118^{*}$ & $0.864^{*}$ & $0.997^{* *}$ & 3.497 & $19.626^{*}$ & 1 & - & - \\
\hline$D R$ & $0.988^{*}$ & $2.554^{*}$ & $1.215^{* *}$ & $0.826^{* *}$ & $-0.001^{* *}$ & $0.758^{* *}$ & 1 & - \\
\hline$E C$ & 1.128 & $-0.784^{*}$ & $0.007^{* *}$ & $0.598^{* *}$ & $0.025^{* *}$ & $0.152^{*}$ & $0.148^{* *}$ & 1 \\
\hline
\end{tabular}


TABLE 7: Correlation statistics between model variables in 2020 .

\begin{tabular}{|c|c|c|c|c|c|c|c|c|}
\hline Variable & EPS & $I C E$ & $C R M$ & $F M L$ & ESIZE & $B S I Z E$ & $D R$ & $E C$ \\
\hline EPS & 1 & - & - & - & - & - & - & - \\
\hline$I C E$ & $2.655^{*}$ & 1 & - & - & - & - & - & - \\
\hline CRM & $0.885^{* * *}$ & $0.900^{*}$ & 1 & - & - & - & - & - \\
\hline$F M L$ & $2.268^{* * *}$ & $2.398^{*}$ & $0.789^{* *}$ & 1 & - & - & - & - \\
\hline$E S I Z E$ & $2.669^{*}$ & $2.362^{*}$ & $1.699^{* * *}$ & $1.380^{* * *}$ & 1 & - & - & - \\
\hline$B S I Z E$ & $9.287^{* *}$ & $2.202^{*}$ & $6.562^{*}$ & $5.569^{*}$ & $19.596^{* *}$ & 1 & - & - \\
\hline$D R$ & $3.336^{*}$ & 5.565 & $7.254^{* *}$ & 1.112 & $0.888^{*}$ & $7.784^{*}$ & 1 & - \\
\hline$E C$ & $5.542^{* *}$ & 21.362 & $2.112^{*}$ & $1.251^{*}$ & $0.283^{*}$ & $2.834^{* *}$ & $4.189^{*}$ & 1 \\
\hline
\end{tabular}

indicates that it is scientific and reasonable to evaluate the performance level of M\&A in an all-round way from a multidimensional perspective. From the analysis of the data changes between the 4 control variables and the explanatory variable EPS, it also shows an overall trend of improvement.

3.3. Regression Analysis. The multivariate linear regression data analysis between variables before and after M\&A of sample enterprises from 2017 to 2020 is shown in Table 8 .

To sum up, there is a high correlation between the changes of multidimensional evaluation index factors selected in this paper and enterprise lean management performance. It is more accurate and reliable to comprehensively evaluate the M\&A effect of enterprises based on multiple dimensions.

3.4. Comparison of Significance Coefficients of Different Methods. The enterprise lean management effect evaluation research method (method 1), enterprise management evaluation method based on evolutionary game model (method 2), and enterprise management evaluation method based on the third-party recycling model (method 3) proposed in this study are used to test respectively. The significance coefficients of indicators selected by different methods are compared. The test results are as shown in Figure 3.

According to the analysis of Figure 3, in multiple iterations, the corresponding significance coefficient of the enterprise management effect evaluation index selected by method 1 is more than 0.8 , the corresponding significance coefficient of the industrial performance evaluation index selected by method 2 is low to 0.4 in the fourth iteration, and the corresponding significance coefficient of the industrial performance evaluation index selected by method 3 is low to 0.5 in the third iteration. Comparing the test results of method 1 , method 2 , and method 3 , it can be seen that the significance coefficient obtained by method 1 is high because this method selects the enterprise management effect evaluation index from the element flow and element composition on the basis of the basic principles of index system construction according to the characteristics of industrial upgrading and scientific and technological production, which improves the rationality of the enterprise management effect evaluation index.
TABLE 8: Multiple linear regression analysis between variables.

\begin{tabular}{lcccc}
\hline \multirow{2}{*}{ Variable } & \multicolumn{4}{c}{ Explained variable EPS } \\
& 2017 & 2018 & 2019 & 2020 \\
\hline$I C E$ & $-0.005^{* *}$ & $0.023^{*}$ & 0.125 & $0.635^{* * *}$ \\
$C R M$ & -0.276 & $-0.005^{* *}$ & 0.236 & $0.551^{*}$ \\
$F M L$ & $0.005^{*}$ & 0.202 & $0.287^{* *}$ & 0.744 \\
ESIZE & -0.178 & $0.066^{*}$ & 0.145 & $0.222^{*}$ \\
BSIZE & $-0.883^{* *}$ & -0.331 & $0.156^{* * *}$ & 1.451 \\
$D R$ & -1.289 & 1.223 & 2.253 & 3.692 \\
$E C$ & $0.980^{*}$ & 0.775 & 0.985 & 1.112 \\
$T$ & 200 & 200 & 200 & 200 \\
\hline
\end{tabular}

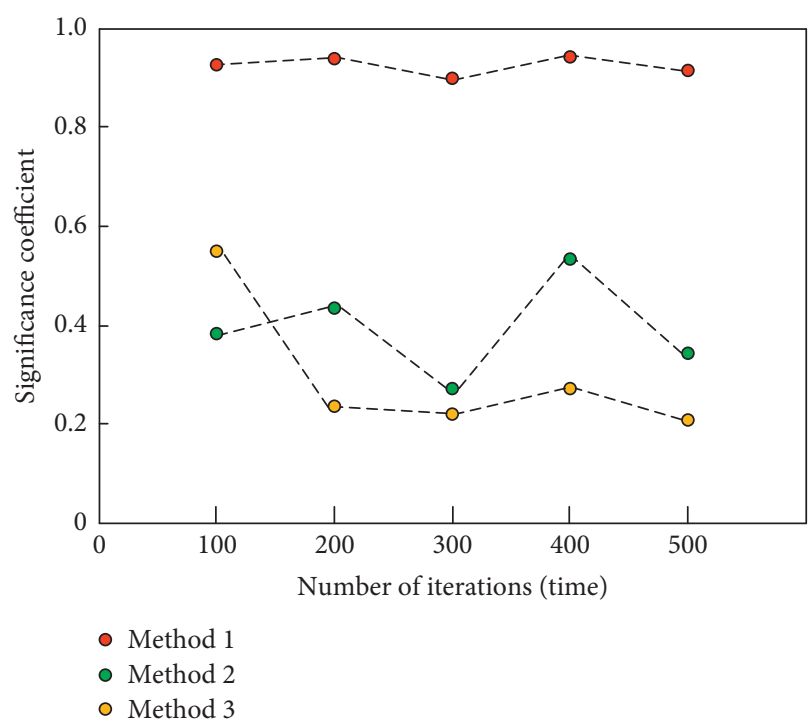

FIgURE 3: Significance coefficients of different methods.

3.5. Comparison of Evaluation Accuracy of Different Methods. Taking the evaluation accuracy as the index, methods 1, 2 , and 3 are tested. The test results are as shown in Figure 4.

Analysis of the data in Figure 4 shows that the evaluation accuracy of method 1 fluctuates between $80 \%$ and $100 \%$, that of method 2 between $40 \%$ and $60 \%$, and that of method 3 between $60 \%$ and $80 \%$. Comparing the test results of method 1 , method 2, and method 3, the evaluation accuracy of method 1 is the highest because the method uses the coefficient of variation method to calculate the weight of the evaluation index of enterprise management effect, improves 


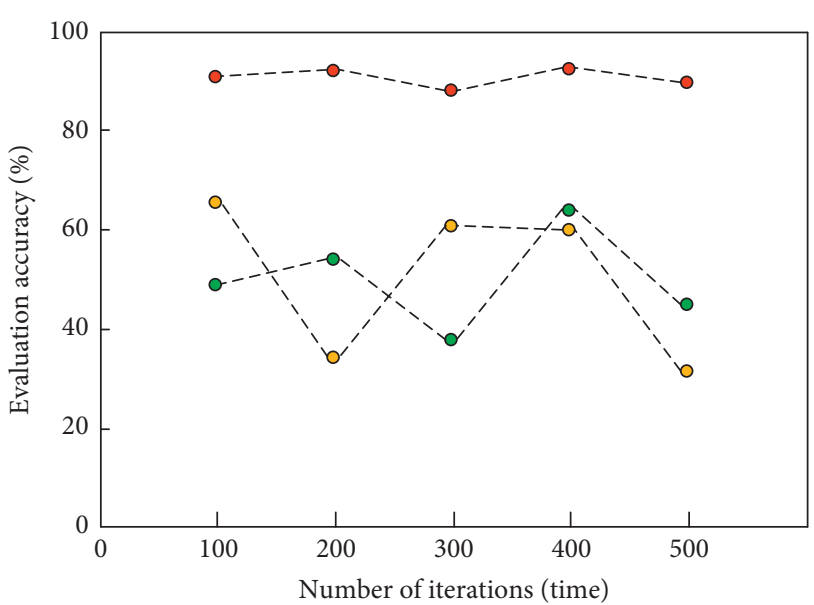

- Method 1

- Method 2

- Method 3

FIGURE 4: Evaluation accuracy of different methods.

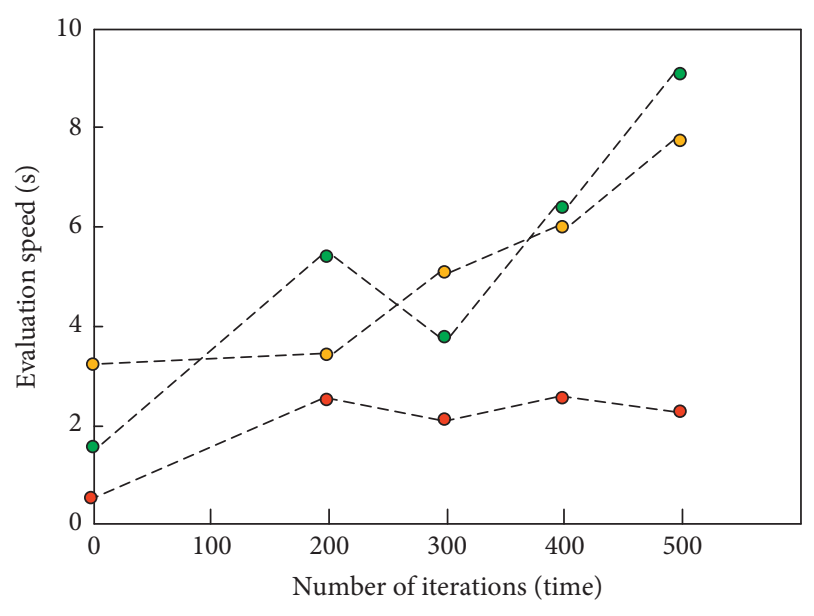

- Method 1

- Method 2

○ Method 3

FIGURE 5: Comparison of evaluation speed of different methods.

the accuracy of weight calculation, and thus improves the evaluation accuracy of method 1.

\subsection{Comparative Test of Evaluation Speed and Satisfaction} with Different Methods. Take the evaluation speed and evaluation satisfaction as comparison indicators to compare the application performance of different methods. The results are shown in Figure 5.

As can be seen from Figure 5, under the eight iterations, the evaluation model constructed by the proposed method is faster, and the time consumption is more stable with the increase of the number of experiments, while the time consumption of other methods is higher and the evaluation speed is slower, which shows that the proposed method has greater advantages in evaluation efficiency. Figure 6 shows that in 500 iterations, the proposed method resulted in

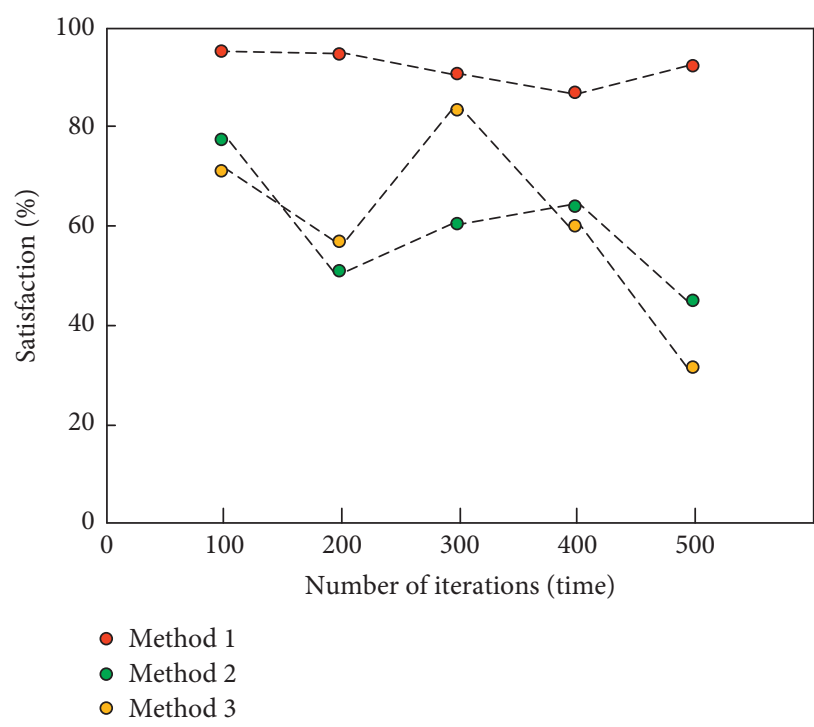

FIGURE 6: Analysis of satisfaction results of evaluation methods.

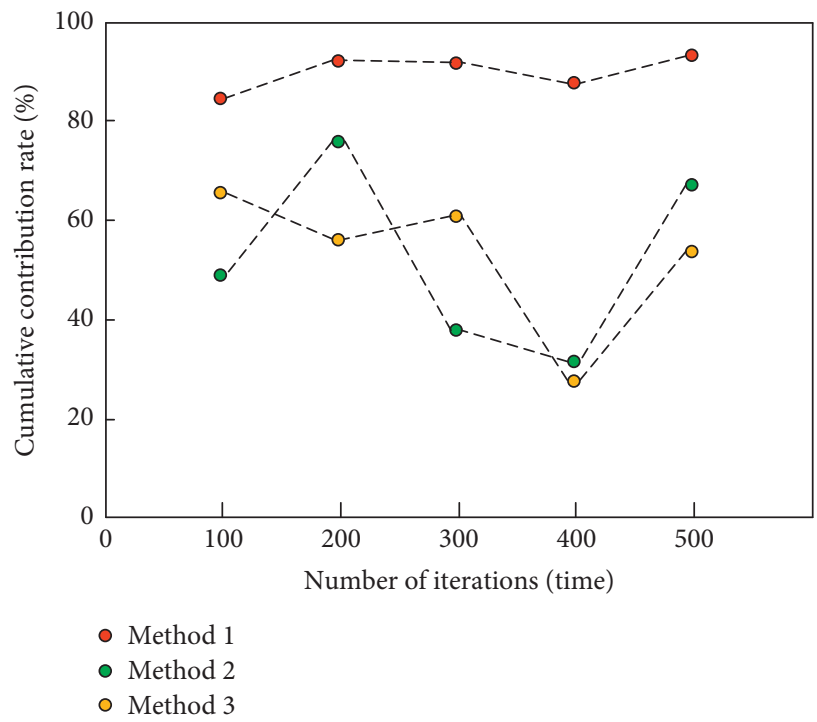

FIgURE 7: Comparison of cumulative contribution rates of different evaluation methods.

higher user satisfaction and a smaller degree of satisfaction fluctuation.

3.7. Comparative Test of Cumulative Contribution Rate and Root-Mean-Square Error of Different Methods. The study adopted the lean management effect evaluation method (Method 1), the evolutionary game model-based enterprise management evaluation method (Method 2), and the thirdparty recycling model-based enterprise management evaluation method (Method 3). The cumulative contribution rate and root-mean-square error of different methods are compared, and the results are used to measure the effectiveness of different methods. The results are shown in Figures 7 and 8 . 


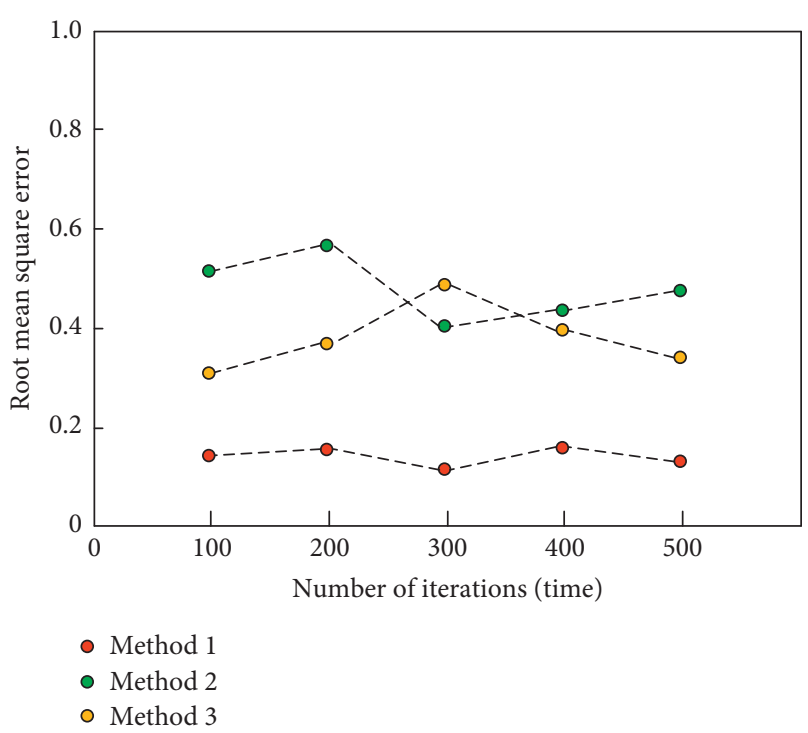

FIGURE 8: Stability comparison of different evaluation methods.

From the experimental results of Figures 7 and 8, it can be seen that compared with the evaluation method based on the evolutionary game model (Method 2) and the evaluation method based on the third-party recycling model (Method 3), the method proposed in this study (Method 1) has a higher cumulative contribution rate and application stability. The cumulative contribution rates of Methods 2 and 3 are low, which indicates that less effective information is obtained in the application of this method, and that indirectly results in the error of evaluation results.

To sum up, there is a high correlation between the changes of multidimensional evaluation index factors selected in this paper and enterprise M\&A performance. It is more accurate and reliable to comprehensively evaluate the effect of enterprise M\&A based on multiple dimensions. The significance coefficient obtained by this method is higher, the evaluation accuracy is higher, and the evaluation speed of the evaluation model is faster, and with the increase of the number of experiments, the time consumption is more stable, with higher cumulative contribution rate and application stability.

\section{Conclusion}

A more accurate evaluation and analysis of the evaluation methods commonly used in enterprise management is conducive to the enterprise in the actual evaluation of a reasonable choice of evaluation methods. This paper puts forward the application research of data mining in enterprise lean management effect evaluation. Through the data mining algorithm to establish the enterprise lean management effect evaluation index system, the index weight is calculated. Association rules and fuzzy set transformation are used to describe the fuzzy boundary of each index and factor, and fuzzy judgment matrix is constructed to evaluate the effect of lean management. Experimental results show that the significance coefficient and precision of the results are high, and the cumulative contribution rate is high, which shows that the proposed method has good practicability.

\section{Data Availability}

The raw data supporting the conclusions of this article will be made available by the corresponding author without undue reservation.

\section{Conflicts of Interest}

The authors declare that they have no conflicts of interest regarding the publication of this work.

\section{References}

[1] C. X. Zhang, "Management innovation of tourism complex development and operation enterprises," Journal of Landscape Research, vol. 11, no. 03, pp. 110-112, 2019.

[2] V. K. Potemkin, "People-oriented management of enterprises and organizations," Economics and Management, vol. 4, no. 2, pp. 165-176, 2020.

[3] Y. Li, Y. X. Liu, G. Y. Zhang, H. Zhu, and S. O. Management, "Selection of cooperative strategies for participating subjects of new R\&D institutions: evolutionary game theory," Science and Technology Management Research, vol. 39, no. 10, pp. 51-55, 2019.

[4] Y. Q. Cheng and Z. D. Xu, "Credit risk evaluation of small enterprises based on revised ELECTRE III by Theil index," Chinese Journal of Management Science, vol. 35, no. 10, pp. 51-55, 2019.

[5] j Z. Zou, N. Zhao, C. R. Lu, and L. Wu, "Complex relational environment non relational distributed large data mining simulation," Computer Simulation, vol. 36, no. 10, pp. 334$338,2019$.

[6] S. Abarajithan and S. V. Mohan, "Cockroach swarm optimization algorithm for high utility association rule mining," International Journal of Swarm Intelligence Research, vol. 12, pp. 459-469, 2021.

[7] I. Sugiyarto, B. Sudarsono, and U. Faddillah, "Performance comparison of data mining algorithm to predict approval of credit card," SinkrOn, vol. 4, no. 1, p. 149, 2019.

[8] K. K. Pandey, D. Shukla, and R. Milan, "Data mining algorithm and new HRDSD theory for big data," International journal of computer sciences and engineering, vol. 7, no. 3, pp. 76-81, 2019.

[9] J. Nalić, G. Martinović, and D. Žagar, "New hybrid data mining model for credit scoring based on feature selection algorithm and ensemble classifiers," Advanced Engineering Informatics, vol. 45, Article ID 101130, 2020.

[10] S. Wahyuni and M. Marbun, "Implementation of data mining in predicting the study period of student using the naïve bayes algorithm," IOP Conference Series: Materials Science and Engineering, vol. 769, no. 1, Article ID 012039, 2020.

[11] Y. Abboud, A. Brun, and A. Boyer, "C3Ro: an efficient mining algorithm of extended-closed contiguous robust sequential patterns in noisy data," Expert Systems with Applications, vol. 131, no. 10, pp. 172-189, 2019.

[12] S. Samsir, S. Suparno, and M. Giatman, "Predicting the loan risk towards new customer applying data mining using nearest neighbor algorithm," IOP Conference Series: Materials 
Science and Engineering, vol. 830, no. 3, Article ID 032004, 2020.

[13] P. Liu, Q. Wang, and W. Liu, "Enterprise human resource management platform based on FPGA and data mining," Microprocessors and Microsystems, vol. 80, Article ID 103330, 2020.

[14] H. Ma, "Enterprise human resource management based on big data mining technology of internet of things," Journal of Intelligent and Fuzzy Systems, vol. 6, no. 1, pp. 1-7, 2021.

[15] Y. Meng, "Establishment and application of Enterprise management maturity model based on multimedia data information systems," Multimedia Tools and Applications, vol. 78, no. 4, pp. 4503-4525, 2019.

[16] B. Arivazhagan and R. Sankara Subramanian, "Hybrid model for pattern discovery in data communication to enhance customer relationship management using data mining $t$," Journal of Physics: Conference Series, vol. 1979, no. 1, Article ID 012048, 2021.

[17] K. Munonye and P. Martinek, "Microservices data mining for analytics feedback and optimization," International Journal of Enterprise Information Systems, vol. 17, no. 1, pp. 22-43, 2021.

[18] A. Barbara, A. Pimonov, and L. Sluder, "A review of methods for processing unstructured data in the assessment of mining personnel," E3S Web of Conferences, vol. 174, no. 1, Article ID 04040, 2020.

[19] S. Selamat, S. Prakoonwit, and W. Khan, "A review of data mining in knowledge management: applications/findings for transportation of small and medium enterprises," SN Applied Sciences, vol. 2, no. 5, pp. 1-15, 2020.

[20] A. Brunello, P. Gallo, E. Marzano, A. Montanari, and N. Vitacolonna, "An event-based data warehouse to support decisions in multi-channel, multi-service contact c," Journal of Cases on Information Technology, vol. 21, no. 1, pp. 33-51, 2019.

[21] O. Moscoso-Zea, J. Castro, J. Paredes-Gualtor, and S. LujanMora, "A hybrid infrastructure of enterprise architecture and business intelligence \& analytics for knowledge management in education," IEEE Access, vol. 7, pp. 38778-38788, 2019.

[22] H. M. Alshira, M. Al-Omari, and B. Igried, "Usability evaluation of learning management systems (LMS) based on user experience," Turkish Journal of Computer and Mathematics Education (TURCOMAT), vol. 12, no. 11, pp. 6431-6441, 2021.

[23] S. Suhartina, L. M. Saleh, S. Sirajuddin, S. Baja, and A. Mallongi, "Evaluation of the application of health and safety management system (SMK3) in the mining company of PTX. Based on government regulation number 50 of 2012," Open Access Macedonian Journal of Medical Sciences, vol. 8, no. T2, pp. 183-187, 2020.

[24] A. Uzun, A. Onur, and S. Alabay, “Students' views on database management systems course designed according to problembased learning," International Journal of Evaluation and Research in Education, vol. 9, no. 1, p. 177, 2020.

[25] T. Fatyani and Z. Yahia, "TAKA news search engine: a proposed DEMO-based performance evaluation system," in Proceedings of the International Conference on Industrial Engineering and Operations Management, Bangkok, Thailand, March 2019.

[26] R. Ramadiani, A. Kurniawan, Z. Arifin et al., "Evaluation of student academic performance using e-learning with the association rules method and the importance of performance analysis," Journal of Physics: Conference Series, vol. 1524, no. 1, Article ID 012107, 2020.

[27] S. Shukla, B. K. Mohanty, and A. Kumar, "A fuzzy approach to prioritise DEA ranked association rules[J]," International
Journal of Business Intelligence and Data Mining, vol. 13, no. 12, pp. 155-176, 2019.

[28] A. Nie, "Design of English interactive teaching system based on association rules algorithm," Security and Communication Networks, vol. 2021, no. 1, pp. 1-10, 2021.

[29] A. Kumar, S. Shukla, and B. K. Mohanty, "A fuzzy approach to prioritize DEA ranked association rules," International Journal of Business Intelligence and Data Mining, vol. 1, no. 1, pp. 1-8, 2019.

[30] B. Keith Norambuena and C. Meneses Villegas, "An extension to association rules using a similarity-based approach in semantic vector spaces," Intelligent Data Analysis, vol. 23, no. 3, pp. 587-607, 2019.

[31] B. S. Neysiani, N. Soltani, N. Soltani, R. Mofidi, and M. H. Nadimi-Shahraki, "Improve performance of association rule-based collaborative filtering recommendation systems using genetic algorithm," International Journal of Information Technology and Computer Science, vol. 11, no. 2, pp. 48-55, 2019.

[32] T. Beridze, A. Cherep, Z. Baranik, V. Korenyev, and I. Vasylchuk, "Analysis of the regression model of the enterprise's financial activity by research on residual error," Naukovyi Visnyk Natsionalnoho Hirnychoho Universytetu, vol. 1, no. 2, pp. 193-197, 2021.

[33] M. Zeeshan, G. Mohapatra, and A. K. Giri, "The effects of non-farm enterprises on farm households' income and consumption expenditure in rural India," Economía Agraria y Recursos Naturales, vol. 19, no. 1, pp. 195-222, 2019.

[34] A. U. Widyaningdyah and L. Ezra, "Enterprise resource planning (ERP) sfor internal control effectiveness," Jurnal Reviu Akuntansi dan Keuangan, vol. 10, no. 2, p. 234, 2020.

[35] M. Kim, K. Sudhir, K. Uetake, and C. Rodrigo, "When salespeople manage customer relationships: multidimensional incentives and private information," Journal of Marketing Research, vol. 56, no. 5, pp. 753-766, 2019.

[36] R. F. Supardianto, R. Ferdiana, and S. Sulistyo, "The role of information technology usage on s financial management and taxation," Procedia Computer Science, vol. 161, pp. 1308-1315, 2019. 